\section{World AIDS Day - December 1, 2018}

World AIDS Day, observed each year on December 1, draws attention to the status of the human immunodeficiency virus/acquired immunodeficiency syndrome (HIV/AIDS) epidemic worldwide. Today, approximately 36.9 million persons worldwide are living with HIV infection, including 1.8 million persons newly infected during 2017 (1). An estimated 940,000 persons worldwide died from AIDS-related illnesses in 2017 (1).

In 2015, an estimated 1.1 million persons in the United States were living with HIV infection, and $86 \%$ were aware of their infection (2).

Through global efforts, including the U.S. President's Emergency Plan for AIDS Relief, for which CDC is an implementing agency, 21.7 million persons worldwide received antiretroviral therapy for HIV infection in 2017, an increase of 2.3 million persons since the end of 2016 (1). A report in this issue of $M M W R(3)$ describes activities to implement the Treat All policy in India, which involves offering antiretroviral therapy to all persons with HIV infection.

\section{References}

1. Joint United Nations Programme on HIV/AIDS. Miles to go. Global AIDS update 2018. Geneva, Switzerland: Joint United Nations Programme on HIV/AIDS; 2018. http://www.unaids.org/sites/ default/files/media_asset/miles-to-go_en.pdf

2. CDC. Estimated HIV incidence and prevalence in the United States, 2010-2015. HIV surveillance supplemental report 2018, vol. 23, no. 1. Atlanta, GA: US Department of Health and Human Services, CDC; 2018. https://www.cdc.gov/hiv/pdf/library/reports/ surveillance/cdc-hiv-surveillance-supplemental-report-vol-23-1.pdf

3. Mitruka K, Bamrotiya M, Agarwal R, et al. Implementation of the Treat All policy among persons living with HIV infection enrolled in care but not on antiretroviral therapy-India, May 2017June 2018. MMWR Morb Mortal Wkly Rep 2018;67:1305-9.

\section{Implementation of the Treat All Policy Among Persons with HIV Infection Enrolled in Care But Not on Antiretroviral Therapy - India, May 2017-June 2018}

Kiren Mitruka, $\mathrm{MD}^{1}$; Manish Bamrotiya, $\mathrm{MBBS}^{2}$; Reshu Agarwal, $\mathrm{MD}^{3}$; Anwar Parvez, $\mathrm{MBBS}^{4}$; Ramesh Reddy Allam, MBBS5; Srilatha Sivalenka, $\mathrm{MA}^{3}$; Pramod Deoraj, $\mathrm{MBBS}^{6}$; Rajendra Prasad, $\mathrm{DD}^{7}$; Uma Devi, $\mathrm{DPH}^{7}$; Padmaja Keskar, $\mathrm{DPH}^{8}$; Shrikala Acharya, $\mathrm{MD}^{8}$; Priya Kannan, $\mathrm{MHA}^{4}$; Ramesam Ganti, MA5; Malay Shah, MD4; Shashikant Todmal, MSW"; Praveen Kumar, MSW5; Nalini Chava, MSc ${ }^{5}$; Ajit Rao, MSW55; Sukarma Tanwar, $\mathrm{MMed}^{3}$; Melissa Nyendak, $\mathrm{MD}^{3}$; Tedd Ellerbrock, $\mathrm{MD}^{1}$; Timothy H. Holtz, $\mathrm{MD}^{3}$; R.S. Gupta, $\mathrm{MD}^{2}$

Since September 2015, the World Health Organization has recommended antiretroviral therapy (ART) for all persons with human immunodeficiency virus (HIV) infection, regardless of clinical stage or CD4 count (1). This Treat All policy was based on evidence that ART initiation early in HIV infection as opposed to waiting for the CD4 count to decline to certain levels (e.g., $<500$ cells $/ \mathrm{mm}^{3}$, per previous guidelines), was associated with reduced morbidity, mortality, and HIV

\section{INSIDE}

1310 Multistate Infestation with the Exotic DiseaseVector Tick Haemaphysalis longicornis - United States, August 2017-September 2018

1314 Health Disparities Among American Indians/Alaska Natives - Arizona, 2017

1319 Outbreak of Dengue Virus Type 2 - American Samoa, November 2016-October 2018

1323 Progress Toward Regional Measles Elimination Worldwide, 2000-2017

1330 QuickStats

Continuing Education examination available at https://www.cdc.gov/mmwr/cme/conted_info.html\#weekly.

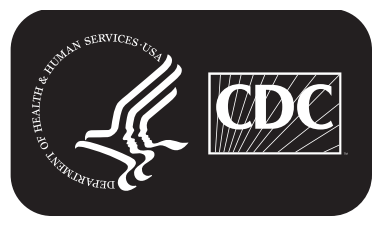

U.S. Department of Health and Human Services Centers for Disease Control and Prevention 